\title{
Enantiomerization and stereoselectivity in bioaccumulation of furalaxyl in Tenebrio molitor larvae
}

\author{
Jing Yin ${ }^{\mathrm{a}, \mathrm{b}}$, Yongxin Gao ${ }^{\mathrm{a}, \mathrm{b}}$, Feilong Zhu ${ }^{\mathrm{a}, \mathrm{b}}$, Weiyu Hao ${ }^{\mathrm{a}, \mathrm{b}}$, Qi Xu ${ }^{\mathrm{a}, \mathrm{b}}$, Huili Wang ${ }^{\mathrm{a}, \mathrm{b}}$, \\ Baoyuan Guo ${ }^{\mathrm{a}, \mathrm{b}, *}$ \\ ${ }^{a}$ Key Laboratory of Environmental Biotechnology, Research Center for Eco-Environmental Sciences, Chinese Academy of Sciences, Beijing 100085, China \\ ${ }^{\mathrm{b}}$ University of Chinese Academy of Sciences, Beijing 100049, China
}

\section{A R T I C L E I N F O}

\section{Keywords:}

Chiral pesticide

Enantiomer

Insect

Enantiomerization

Enantioselectivtiy

\begin{abstract}
A B S T R A C T
Furalaxyl is a chiral pesticide and widely used in modern agriculture as racemate mixture. The enantiomerization and enantioselecive bioaccumulation by a single dose of furalaxyl to Tenebrio molitor larvae under laboratory conditions were studied using a high-performance liquid chromatography tandem mass spectroscopy method based on a ChiralPAK IC column. Our results showed that a significant enantiomerization (interconversion between R-enantiomer and S-enantiomer) was observed in Tenebrio molitor larvae under R- or Sfuralaxyl exposure. Though the two furalaxyl enantiomers exhibited low-capacity of bioaccumulation in Tenebrio molitor larvae, bioaccumulation of rac-furalaxyl was enantioselective with a preferential accumulation of Sfuralaxyl at $10 \mathrm{mg} / \mathrm{kg}$ dosage exposure. In addition, enantiomerization and enantioselective degradation of the two enantiomers was not observed in wheat bran. These results showed that enantioselectivtiy of furalaxyl enantiomers was an important process combined with degradation, metabolism and enatiomerization in organisms.
\end{abstract}

\section{Introduction}

About $40 \%$ of currently registered pesticides are chiral and the proportion is expected to increase as compounds with more complex structures are introduced (Lewis et al., 1999; Garrison, 2006; Ye et al., 2010). Chiral pesticides have different bioavailability, distribution, metabolic and excretion behavior due to enantioselectivity of enantiomers (Maier et al., 2001). Consequently, attention has recently been focused on the enantioselective behavior of chiral pesticides in the environment (Müller and Kohler, 2004; Genualdi et al., 2009; Xu et al., 2009). However, most of the chiral pesticides have been manufactured and applied to agro-ecosystems as racemate mixture, whereas considering only the racemates does not sufficiently describe its actual environmental fate and ecological risks. In order to decrease application rates and thus release smaller amounts of chemicals into the environment, adopting biologically active enantiopure products in place of racemic products was proposed by green chemistry advocators.

Some chiral pesticides are configurationally unstable and undergo enantiomerization (see Table S1) (Liu et al., 2005; Qin and Gan, 2007; Nillos et al., 2009; Li et al., 2011; Sun et al., 2013; Gao et al., 2013, 2014; Wang et al., 2014, 2017). It is important to obtain the information on the stability of individual enantiomers of a chiral pesticide when assessing the possibility of developing a single enantiomer as a commercial pesticide (Diao et al., 2009).

Furalaxyl is a systemic acetanilide fungicide that is used for prevention and treatment of plant diseases caused by pathogens of the Oomycota (Cabras et al., 1985; Price and Fox, 1986; Rouchaud et al., 1989; Zhang et al., 2012). The compound consists of a single pair of enantiomers with R- and S-configuration (Fig. 1) and is marketed as a racemate mixture. Although furalaxyl has been widely used in modern agriculture, enantioselective behavior of the furalaxyl enantiomers in organisms has not been documented, especially in insects.

Insects play a vital role in the food chain and the global eco-system of the planet (Wiegert and Evans, 1967). Pesticides would be indirectly transferred to higher trophic levels through predation insects and food chain while these chemicals are widely abused in environment. Tenebrio molitor (T. molitor) is an important economic pest in stored grain products. Their larvae are used as a model pest in the fields of environmental toxicology, genetics and so on (Kostaropoulos et al., 2001; Prabhakar et al., 2007). In our previous studies, enantioselective processes have been observed in T. molitor under chiral pesticides exposure such metalaxyl, benalaxyl, diniconazole and epoxiconazole. To further understand the enantioselectivity of chiral pesticides in organisms, it is necessary to investigate the effect of the furalaxyl enantiomers on $T$.

\footnotetext{
* Corresponding author at: Key Laboratory of Environmental Biotechnology, Research Center for Eco-Environmental Sciences, Chinese Academy of Sciences, Beijing 100085, China.

E-mail address: guoby@rcees.ac.cn (B. Guo).
} 


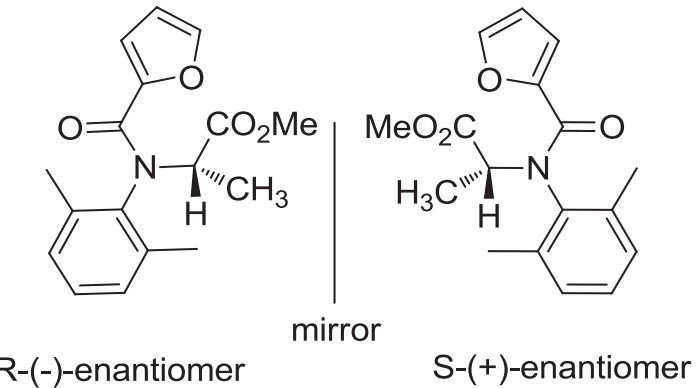

Fig. 1. Structures of furalaxyl enantiomers.

molitor comprehensively.

In this study, an effective method for stereoselective determination of furalaxyl residues in T. molitor larvae and wheat bran using highperformance liquid chromatography tandem mass spectrometry (HPLCMS/MS) was developed. Enantiopure furalaxyl enantiomers were employed to elucidate potential enantiomerization and enantioselective bioaccumulation in T. molitor. The main goal of the present study was to emphasize the importance of enantiomerization in the environmental fate and behavior of chiral pesticides and to fill up the data gaps to accurately evaluate the potential effects of the furalaxyl enantiomers in organisms.

\section{Material and methods}

\subsection{Chemicals and reagents}

Standard rac-furalaxyl ( $>98.0 \%$ purity) was purchased from Sigma-Aldrich (St. Louis, MO, USA). Enantiopure enantiomers standard of R- and S-furalaxyl were prepared via chiral synthesis methods. Methanol (HPLC grade), n-hexane (HPLC grade), acetonitrile (HPLC grade), alumina-N-solid-phase extraction (alumina-N-SPE) cartridge and filter membrane (pore size, aperture: $0.22 \mu \mathrm{m}$, diameter: $13 \mathrm{~mm}$ ) were purchased from Dikma Company (Beijing, China). Pyridine, trifluoromethanesulfonic anhydride, methyl (S)-(-)-lactate, methyl (R)(+)-lactate, 2, 6-dimethyl aniline, 2-furoyl chloride, sodium bicarbonate, toluene, dichloromethane $\left(\mathrm{CH}_{2} \mathrm{Cl}_{2}\right)$, ether, ethyl acetate, acetone, acetonitrile (analytical grade) and anhydrous sodium sulfate $\left(\mathrm{Na}_{2} \mathrm{SO}_{4}\right)$ were purchased from Beijing Chemical Reagent Co. Ltd (Beijing, China).

\subsection{HPLC-MS/MS conditions}

HPLC was performed using Thermo ACCELA series (Thermo Electron Corporation, Hopkinson, MA) equipped with ACCELA Autosampler. Enantiomers were separated on a ChiralPAK IC [cellulosetris-(3, 5-dichlorophenyl-carbamate)]. The mobile phase was a mixture of acetonitrile/water (80/20, v/v) with a flow rate of $0.4 \mathrm{~mL} / \mathrm{min}$. Chromatographic separation was conducted at $20^{\circ} \mathrm{C}$ and the injection volume was $1 \mu \mathrm{L}$.

TSQ QUANTUM ACCESS MAX was used for LC-MS/MS analysis (Thermo Electron Corporation, Hopkinson, MA). The optimized major working parameters were provided in support information (Table S2). For furalaxyl, transition $\mathrm{m} / z 302 \rightarrow 95$ was used for confirmation, $\mathrm{m} / \mathrm{z}$ $302 \rightarrow 242$ was used for quantification, and collision energies were $30 \mathrm{eV}$ and $16 \mathrm{eV}$, respectively. The signals were received and processed with Thermo Xcalibur 2.2 SP1.48 software.

\subsection{Chiral synthesis of the two enantiomers of furalaxyl}

Given the difference activity between R- and S-furalaxyl in biochemical effects, obtaining enantiopure enantiomers standards was necessary. The two enantiomers of furalaxyl were prepared via modified chiral synthesis methods according general procedure (Effenberger et al., 1986; Palla et al., 2001).

Briefly, pyridine $(1.42 \mathrm{~mL}, 17.6 \mathrm{mmol}, 1.1$ equiv) in $30 \mathrm{~mL}$ of $\mathrm{CH}_{2} \mathrm{Cl}_{2}$ was cooled to $0{ }^{\circ} \mathrm{C}$, trifluoromethanesulfonic anhydride $(2.8 \mathrm{~mL}$, $16.2 \mathrm{mmol}, 1.05$ equiv) was added, and the resulting mixture was stirred over $10 \mathrm{~min}$. Methyl (S)-(-)-lactate $(1.53 \mathrm{~mL}, 16.0 \mathrm{mmol}, 1$ equiv) was added dropwise. The reaction mixture was stirred at $0{ }^{\circ} \mathrm{C}$ for $30 \mathrm{~min}$ and then warmed to room temperature. The mixture was filtered, and the filter cake was washed with ether. The filtrate was evaporated in vacuo $\left(<25^{\circ} \mathrm{C}\right)$, and the residue was triturated with ether and filtered. After evaporating the solvent, the residue was dissolved in $20 \mathrm{~mL}$ of dichloromethane and 2, 6-dimethyl aniline (1.97 mL, $16.0 \mathrm{mmol}, 1$ equiv) was added. The reaction solution was stirred at room temperature overnight. Removal of the solvent in vacuo followed by flash chromatography gave the light yellow oil which $\mathrm{N}$ xylyl-D-methyl alaninate $(2.76 \mathrm{~g})$.

Sodium bicarbonate $(0.5 \mathrm{~g}, 6 \mathrm{mmol}, 1.1$ equiv) was added to a solution of N-xylyl-D-methyl alaninate $(1.12 \mathrm{~g}, 5.5 \mathrm{mmol}, 1$ equiv) in $30 \mathrm{~mL}$ of toluene, cooled to a temperature ranging from 5 to $10{ }^{\circ} \mathrm{C}$, and subsequently 2 -furoyl chloride $(0.93 \mathrm{~g}, 6 \mathrm{mmol}, 1.1$ equiv) was slowly added dropwise. After $4 \mathrm{~h}$ at room temperature, the above solution was washed with saturated sodium chloride and the organic phase was evaporated in vacuo. The obtained crude product was crystallized with hexane to give $1.2 \mathrm{~g}$ of white crystalline solid alaninate with an enatiomeric $\mathrm{R} / \mathrm{S}$ ratio $=97$ (yield 68\%).

Synthesis of S-furalaxyl with Methyl (R)-(+)-lactate as a starting material followed the same experimental procedure. The structures of R- and S-furalaxyl were confirmed by comparing with mass spectrum of furalaxyl standard. The optical purities of R-enantiomer and S-enantiomer were $98.0 \%$ and $98.4 \%$, respectively.

\subsection{T. molitor larvae}

T. molitor larvae were purchased from Beijing Jie Matt Biological Technology Co., LTD and were reared in ventilated terraria $(25 \times 15 \times$ $20 \mathrm{~cm}$ ). A layer of wheat bran covered the terrarium floor. The population was kept at $25{ }^{\circ} \mathrm{C}, 80 \%$ humidity and the light cycle adopted was $16 \mathrm{~h}$ light and $8 \mathrm{~h}$ dark.

\subsection{Wheat bran formulation and T. molitor larvae exposure}

To ensure that the rac-furalaxyl was dispersed uniformly in the $100 \mathrm{~g}$ dry weight of wheat bran, we did the procedure in steps (dilution spike). First, rac-furalaxyl was dissolved in acetonitrile to make a stock solution at a concentration of $1000 \mathrm{mg} / \mathrm{L}$. Next, $1 \mathrm{~mL}$ of stock $(1000 \mathrm{mg} / \mathrm{L})$ was dissolved into $50 \mathrm{~mL}$ of acetone. Thereafter, $100 \mathrm{~g}$ of wheat bran was soaked in the $50 \mathrm{~mL}$ of acetone solution of rac-furalaxyl, followed by drying in fuming cupboard overnight. The final concentration of rac-furalaxyl in wheat bran was $10 \mathrm{mg} / \mathrm{kg}$. The wheat bran fortified with the enantiopure R-furalaxyl and S-furalaxyl followed the same experimental procedure.

In this experiment, the $T$. molitor was used with the larval stage ( $0.1 \mathrm{~g}$ mean body weight). Moulting or pupating larvae were excluded from the experiment. Before the larvae were introduced, they were fed with unfortified wheat bran for 1 week to acclimate. A piece of paper resting on top of the bran provided cover for the worms. Thirty grams of T. molitor larvae were exposed to the chemical in each ventilated terrarium containing $7 \mathrm{~g}$ of contaminated wheat bran. For exposure experiment, each ventilated terrarium containing $7 \mathrm{~g}$ wheat bran which were contaminated by R-, S- or rac-furalaxyl separately exposed to $30 \mathrm{~g}$ wet weight of $T$. molitor larvae, respectively. Food was renewed once a week. All of the plastic terraria were placed in the dark in an environmental chamber to keep consistent environmental condition.

For the uptake experiment, $1 \mathrm{~g}$ of $T$. molitor larvae (approximately 8 to 10 worms) and $0.5 \mathrm{~g}$ of wheat bran were collected at $1,3,9,24,72$, 168, 336 and $504 \mathrm{~h}$ exposure, and three parallel samples were prepared at each time point. Wheat bran on the surface of worms was removed by 

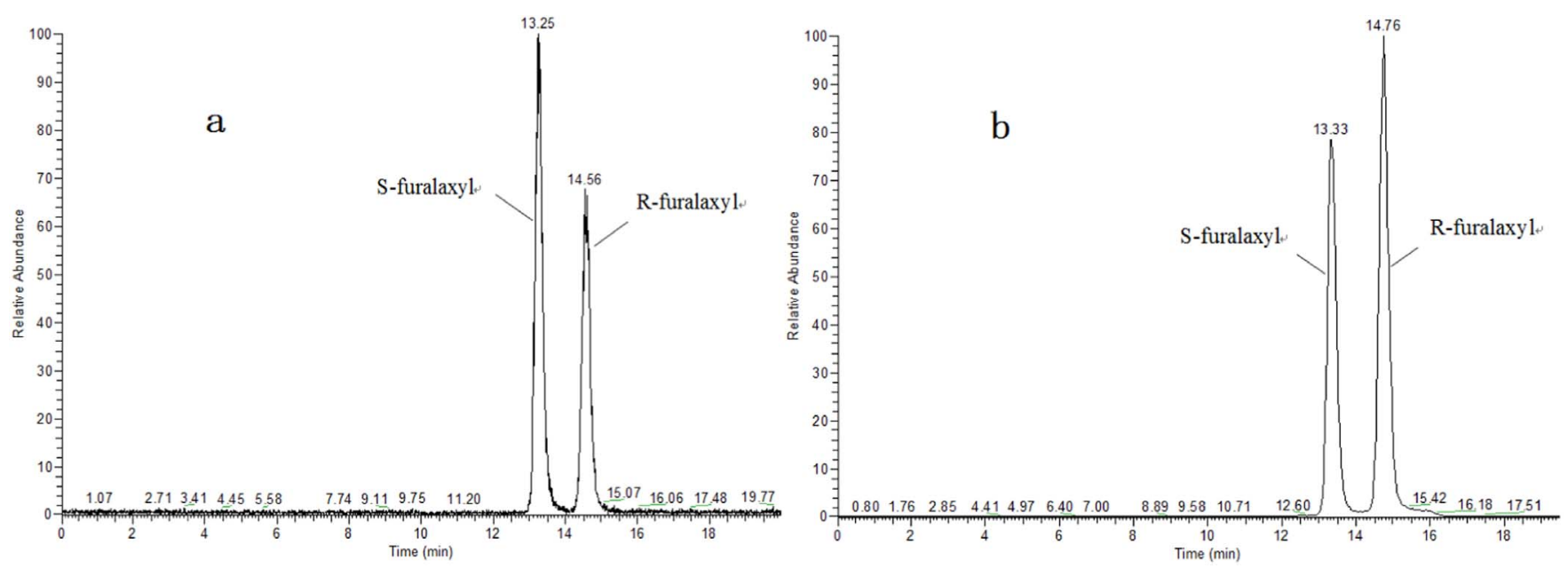

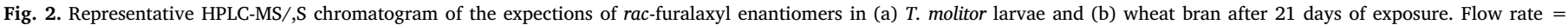
$0.4 \mathrm{~mL} / \mathrm{min}$, ultrapure water: acetonitrile $=20: 80(\mathrm{v} / \mathrm{v})$.

a sieve, and the worms were frozen at $-20^{\circ} \mathrm{C}$ in $50 \mathrm{~mL}$ of polypropylene centrifuge tube. The samples of wheat bran collected from uptake experiment were analyzed the enantioselective degradation of rac-furalaxyl in wheat bran, simultaneously. For the degradation assay of rac-furalaxyl in T. molitor larvae, the method was carried out as following. The T. molitor larvae were partially transferred to uncontaminated wheat bran and collected after 0, 0.5, 1, 1.5, 2 days. Three parallel samples were prepared at each time point. Wheat bran samples from each plastic terrarium were also stored at $-20^{\circ} \mathrm{C}$. All experiments were performed at $25 \pm 0.5^{\circ} \mathrm{C}$.

\subsection{Analysis of Furalaxyl Residue}

Wheat bran pretreatment: $15 \mathrm{~mL}$ of acetonitrile was added to a $50 \mathrm{~mL}$ polypropylene centrifuge tube containing $0.5 \mathrm{~g}$ wet weight of incubated wheat bran sample. Next, the tube was shaken for $3 \mathrm{~min}$ on a vortex mixer, exposed to ultrasonic vibration for $10 \mathrm{~min}$ and then centrifuged at $3000 \mathrm{r} / \mathrm{min}$ for $5 \mathrm{~min}$. The solvent extract was transferred to a new tube. The remaining material was extracted again and the two extracts combined. The combined extract was filtered through anhydrous sodium sulfate $(5 \mathrm{~g})$ into a pear-shaped flask and evaporated to dryness by vacuum rotary evaporator at $35{ }^{\circ} \mathrm{C}$. A alumina-N-SPE cartridge was used to clean up other interfering substances. The cartridge was preconditioned by rinsing with $5 \mathrm{~mL}$ of ethyl acetate followed by $5 \mathrm{~mL}$ of $\mathrm{n}$-hexane and equilibrated with $5 \mathrm{~mL}$ of ethyl acetate/ $\mathrm{n}$-hexane (1:4). The dry extract was dissolved in $2 \mathrm{~mL}$ of $20 \%$ ethyl acetate in n-hexane, and then, the solution was passed through the alumina-N-SPE cartridge. The cartridge was eluted with an additional $8 \mathrm{~mL}$ of $1: 3$ ethyl acetate/n-hexane. The combined $10 \mathrm{~mL}$ of eluate was collected in a pear-shaped flask and evaporated to dryness in vacuo at $35^{\circ} \mathrm{C}$ and the dry extract was redissolved in $1 \mathrm{~mL}$ acetonitrile and passed through a filter membrane.

The pretreatment method for the T. molitor larvae is essentially the same as the wheat bran with a few minor changes. The wet weight of $T$. molitor larvae sample was one gram. For cleanup (fat destruction), $3 \times$ $10 \mathrm{~mL}$ of $\mathrm{n}$-hexane was added for liquid-liquid partition to extract most of the lipid. The upper layer of $n$-hexane was discarded, and the layer of acetonitrile was evaporated to dryness by vacuum rotary evaporator. An alumina-N-SPE cartridge was used to clean up other interfering substances. The cartridge was preconditioned by rinsing with $5 \mathrm{~mL}$ of ethyl acetate followed by $5 \mathrm{~mL}$ of $\mathrm{n}$-hexane and equilibrated with $10 \mathrm{~mL}$ of 1:5 ethyl acetate: $n$-hexane. The sample of dry extract was dissolved in $2 \mathrm{~mL}$ of $25 \%$ ethyl acetate in $\mathrm{n}$-hexane, and then, the solution was passed through the alumina-N-SPE cartridge. The cartridge was eluted with additional $8 \mathrm{~mL}$ of 1:3 ethyl acetate: $\mathrm{n}$-hexane.

\subsection{Data analysis}

The degradation rate constant of the furalaxyl enantiomers in wheat bran and T. molitor larvae was estimated using the pseudo-first-order kinetic expression (1):

$\ln \left(\frac{\mathrm{C}}{\mathrm{C}_{0}}\right)=-\mathrm{kt}$

The half-life $\left(\mathrm{t}_{1 / 2}\right)$ was determined using regression plots of In (C/ $\mathrm{C}_{0}$ ) versus time $(\mathrm{t})$ :

$t_{1 / 2}=\frac{\ln 2}{k}$

Wherein $\mathrm{C}_{0}$ is the initial concentration of enantiomer $(\mathrm{mg} / \mathrm{kg}), \mathrm{C}$ is the concentration $(\mathrm{mg} / \mathrm{kg}$ ) at time $\mathrm{t}$ (hours), and $\mathrm{k}$ is the degradation rate constant.

The enantiomeric fraction (EF) was employed to measure the enantioselective degradation or bioaccumulation of rac-furalaxyl in wheat bran and T. molitor larvae. The EF values defined range from 0 to 1 , with $\mathrm{EF}=0.5$ representing the racemic mixture (Geus et al., 2000). EF was expressed as follows:

$\mathrm{EF}=\frac{[\mathrm{S}]}{[\mathrm{R}]+[\mathrm{S}]}$

Bioaccumulation factor (BAF) was employed to further illustrate the enantioselective bioaccumulation of the furalaxyl enantiomers. BAF is a function of relative sorptive capacities of organism versus the surrounding food, and it is defined as:

$\mathrm{BAF}=\frac{\mathrm{C}_{\mathrm{T}}}{\mathrm{C}_{\mathrm{WB}}}$

$\mathrm{C}_{\mathrm{T}}$ is the concentration of compound in T. molitor larvae tissue and $\mathrm{C}_{\mathrm{WB}}$ is the concentration of compound in wheat bran.

\section{Results and discussion}

\subsection{Assay validation}

The analysis results of furalaxyl in T. molitor larvae and wheat bran showed that R- and S-furalalxyl were well separated with no interfering peaks through validated HPLC-MS/MS method (Fig. 2). Calibration curves were linear between 0.01 and $1.0 \mathrm{mg} / \mathrm{L}$, with correlation coefficients $\left(\mathrm{r}^{2}\right)$ for R- and S-furalaxyl of 0.998 and 0.999 , respectively. Uncontaminated T. molitor larvae wheat bran samples were fortified with $0.1,0.5$, and $1 \mathrm{mg} / \mathrm{kg}$ of the two furalaxyl enantiomers. The 
a

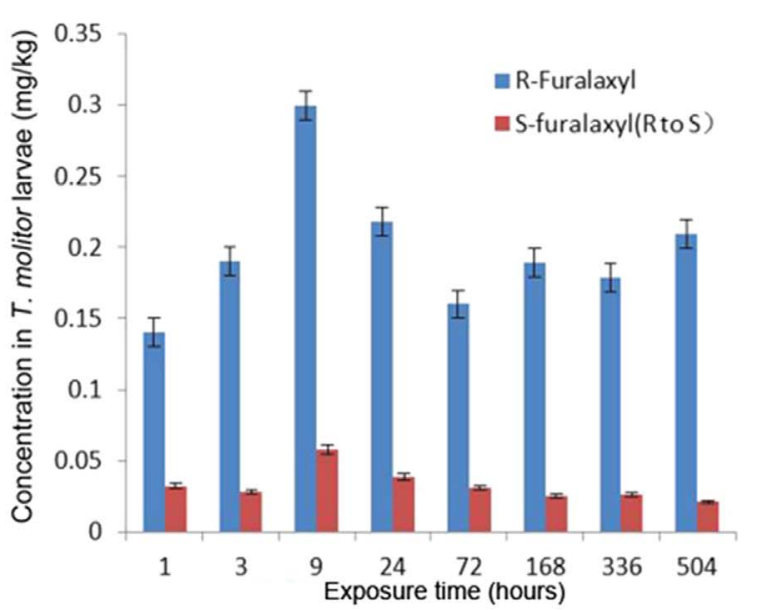

b

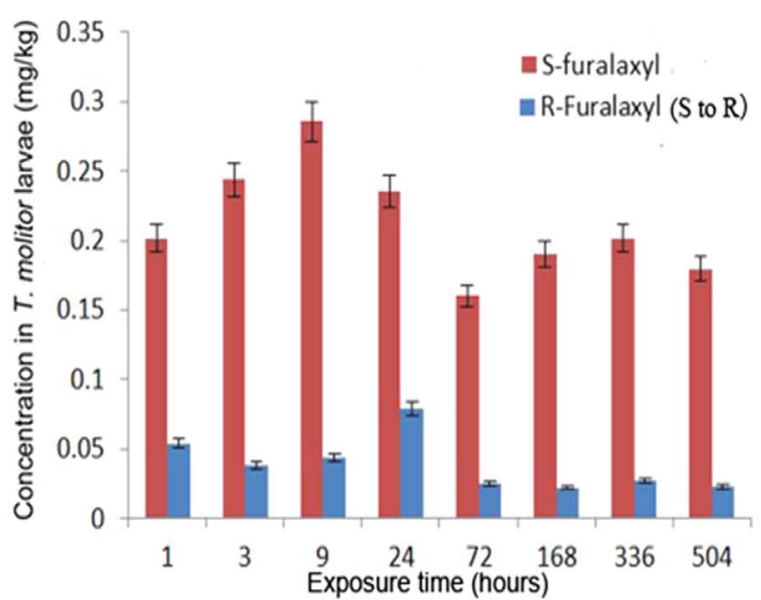

Fig. 3. Enatiomerization of enantiopure R-furalaxyl (a) and enantiopure S-furalaxyl (b) in T. molitor larvae. Values are represented as mean \pm SD ( $n=3$ at each time point).
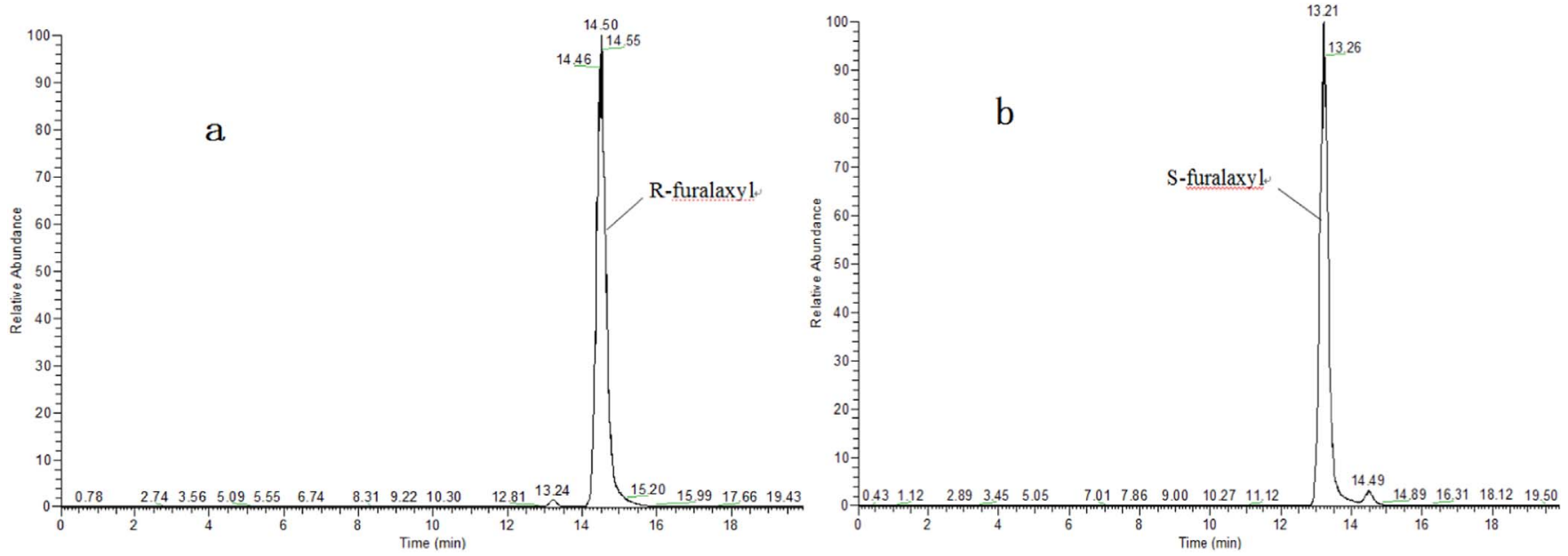

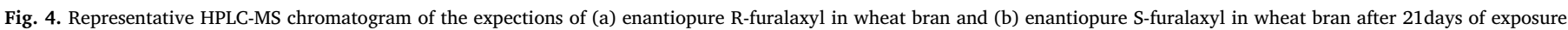
Flow rate $=0.4 \mathrm{~mL} / \mathrm{min}$, ultrapure water: acetonitrile $=20: 80(\mathrm{v} / \mathrm{v})$.
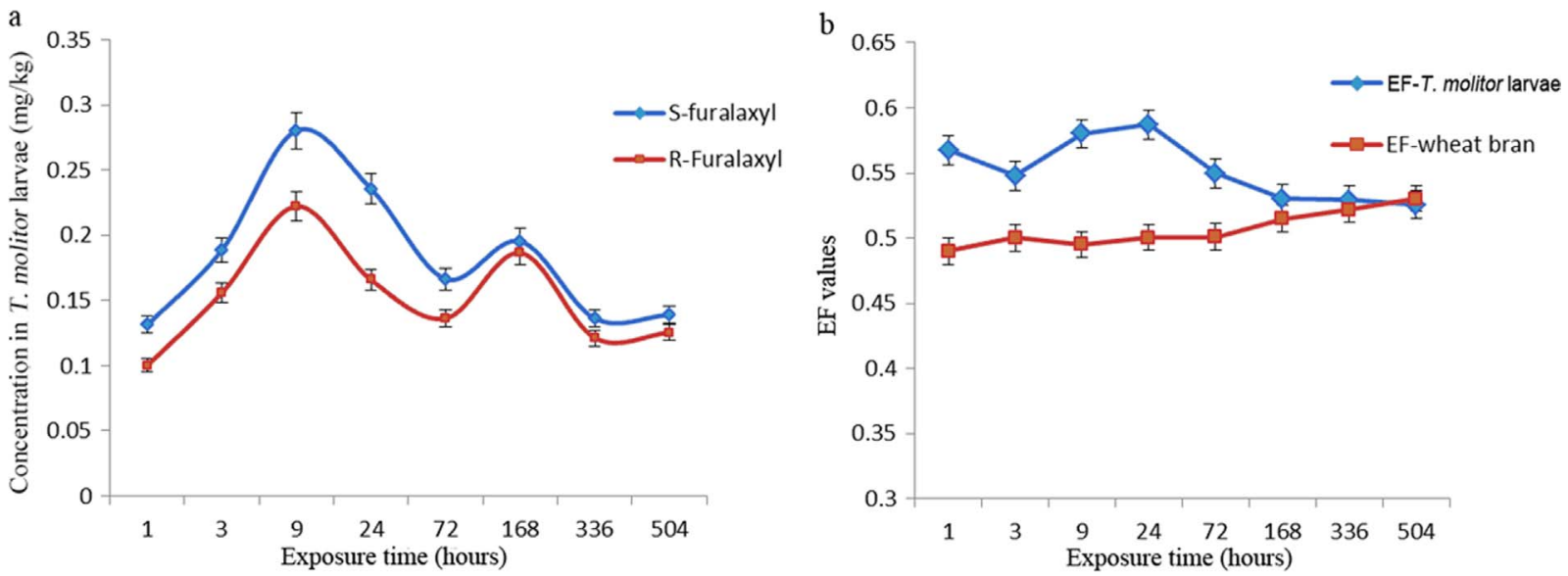

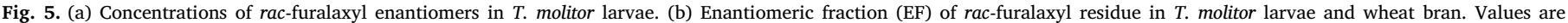
represented as mean $\pm \mathrm{SD}$ ( $\mathrm{n}=3$ at each time point).

average recoveries for both enantiomers ranged between $86 \%$ and $94 \%$ in T. molitor larvae and between $90 \%$ and $95 \%$ in wheat bran. The relative standard deviations (RSDs) ranged from $2.6 \%$ to $7.2 \%$ in T. molitor larvae, and $2.1-3.7 \%$ in wheat bran. Based on the peak-to-peak signal to noise ratio of 3 , the limit of detection of the method was $0.01 \mathrm{mg} / \mathrm{kg}$ both in T. molitor larvae and wheat bran.

\subsection{Enantiomerization in Tenebrio molitor larvae}

Wheat bran contaminated with enantiopure R-furalaxyl or S-furalaxyl was fed to larvae to evaluate the enantiomerization of furalaxyl enantiomers in T. molitor larvae. For the enantiopure R-furalaxyl, obvious enantiomerization from $\mathrm{R}$ to $\mathrm{S}$ was observed at every exposure time (Fig. 3a). The concentration of R-furalaxyl rapidly increased 
Table 1

Calculated BAF for enantiomers of furalaxy.

\begin{tabular}{|c|c|c|c|c|c|c|c|c|}
\hline & \multicolumn{8}{|c|}{ Exposure time (hours) } \\
\hline & 1 & 3 & 9 & 24 & 72 & 168 & 336 & 504 \\
\hline BAF-S-furalaxyl & $0.027 \pm 0.002$ & $0.039 \pm 0.004$ & $0.058 \pm 0.011$ & $0.049 \pm 0.009$ & $0.035 \pm 0.014$ & $0.045 \pm 0.012$ & $0.028 \pm 0.007$ & $0.029 \pm 0.006$ \\
\hline BAF-R-furalaxyl & $0.021 \pm 0.001$ & $0.032 \pm 0.007$ & $0.042 \pm 0.010$ & $0.035 \pm 0.015$ & $0.028 \pm 0.008$ & $0.039 \pm 0.011$ & $0.025 \pm 0.013$ & $0.026 \pm 0.009$ \\
\hline
\end{tabular}

during $9 \mathrm{~h}$ because contaminated wheat bran was uptake by T. molitor larvae. From 9 to 72 h, R-furalaxyl affected the larvae feeding ability resulting in the concentration rapidly decreased. Recovery of feeding capacity contributed to concentration increased again after $72 \mathrm{~h}$ exposure. The highest level $(0.30 \mathrm{mg} / \mathrm{kg})$ of R-furalaxyl was reached at the time of $9 \mathrm{~h}$. The highest concentration of transformed S-furalaxyl reached $0.051 \mathrm{mg} / \mathrm{kg}$, simultaneously. The concentrations of R-furalaxyl and S-furalaxyl decreased after $9 \mathrm{~h}$ exposure and reached a relatively steady-state level in 168-504 h.

Enantiomerization of enantiopure from $\mathrm{S}$ to R-furalaxyl in T. molitor larvae was also observed, and the trend of the concentration change of S-furalaxyl was similar to that of R-furalaxyl (Fig. 3b). Conversely, the highest concentration of transformed R-furalaxyl $(0.076 \mathrm{mg} / \mathrm{kg})$ appeared $24 \mathrm{~h}$. These results suggest that furalaxyl enantiomers initially underwent significant enantiomerization at a fast rate in T. molitor larvae. In the later phase of exposure, the extent of enantiomerization was reduced due to the continuous uptake of major enantiomer and degradation of minor enantiomer. However, eantiomerization of the two furalaxyl enantiomers was not observed in the wheat bran during 21 days (Fig. 4).

Enzyme-mediated enantiomerization has been extensively studied for pharmaceuticals (Hutt and Caldwell, 1983; Testa et al., 1993), amino acids, and sugars (Friedman, 1999) with respect to its mechanism. The inversion of stereochemistry in a chiral chemical is generally catalyzed by racemases or epimerases through cleavage of the methane $\mathrm{C}-\mathrm{H}$ bond adjacent to a carbonyl group followed by its reformation or successive oxidation-reduction at a chiral center (Tarrier et al., 1999). The chiral carbon of furalaxyl holds an electron-withdrawing carbonyl group and a conjugated acetanilide functional group (Fig. 1). Therefore, the proton on the chiral center is relatively acidic and is thus easily lost to create an intermediate carbanion. Under protic environment, reprotonation regenerates the parent compound from either the top or the bottom face of the anion, thus interconverts enantiomers.

\subsection{Enantioselective bioaccumulation in Tenebrio molitor larvae}

Enantioselective bioaccumulation in T. molitor larvae was investigated with rac-furalaxyl. The concentrations of the two furalaxyl enantiomers in T. molitor larvae were determined. Initially, rapid uptake of the two furalaxyl enantiomers was observed in T. molitor larvae (Fig. 5a). Concentrations of the two enantiomers both reached the highest level in $9 \mathrm{~h}$. A rapid decrease of concentrations was observed after $9 \mathrm{~h}$. Finally, the concentrations tended to stability after 14 days. A significant difference was observed between the concentrations of two enantiomers in T. molitor larvae tissue at all sample points, with concentration of the S-furalaxyl higher than that of the R-furalaxyl (Fig. 5a). In addition, EF values deviated from 0.5 in the bioaccumulation experiment during 21 days of exposure and reached the highest level in $24 \mathrm{~h}$ and finally maintained approximately 0.53 (Fig. 5b). That is, the bioaccumulation of furalaxyl in T. molitor larvae was expected to be an enantioselective process with the preferential bioaccumulation of S-furalaxyl.

To further illustrate the bioaccumulation of the furalaxyl enantiomers, the BAF was employed. There was a significant difference in the BAF between the two enantiomers of furalaxyl (Table 1). The BAF value of the S-enantiomer was larger than that of the R-enantiomer once more suggesting that the S-enantiomer is likely to be preferentially accumulated in T. molitor larvae. Both the furalaxyl enantiomers exhibited the low capacity of bioaccumulation in T. molitor larvae, which could be attributed to a small amount of furalaxyl taken up by T. molitor larvae, the low lipophicity of furalaxyl and degradation at a high rate. Thus, enantiomerization could be considered as one of the most important causes which lead to enantioselective bioaccumulation of furalaxyl in T. molitor larvae. Given the enantioselective degradation and enatiomerization of furalaxyl in T. molitor larvae, the behavior of each enantiomer of racemate mixture should be ideally examined with enantiomerization to more correctly assess the safety in ecotoxicology on the most sensitive species. Enantioselectivity could make the environmental behavior and ecological effects of racemate mixture complicated (Diao et al., 2009).

\subsection{Enantioselective degradation in wheat bran or Tenebrio molitor larvae}

Contaminated wheat bran samples were evaluated the enantioselective degradation of rac-furalaxyl in wheat bran. Concentrations of R- and S-furalaxyl almost unchanged in wheat bran. The final concentrations of R- and S-furalaxyl were $4.78 \pm 0.52 \mathrm{mg} / \mathrm{kg}$ and $4.77 \pm 0.27 \mathrm{mg} / \mathrm{kg}$ after $504 \mathrm{~h}$ exposure. Because enantiopure Rand S-furalaxyl did not undergo enantiomerization in wheat bran, the decrease in the furalaxyl enantiomers must result from non-enzymatic reaction such as abiotic isomerism and volatilization. The EF values of two enantiomers in wheat bran were not obviously observed to deviate from 0.5 in 21 days (Fig. 5b). This result indicated that rac-furalaxyl did not enantioselective degrade in wheat bran. It has been demonstrated in other acetanilide fungicide such as metalaxyl and benalaxyl (Gao et al., 2013 , 2014). In addition, the result of degradation assay of rac-furalaxyl indicated that R- and S-furalaxyl were faster degraded in $T$. molitor larvae (Table S3). The half-life $\left(\mathrm{T}_{1 / 2}\right)$ of R- and S-furalaxyl in $T$. molitor larvae were 1.47 day and 1.23 day, respectively. Although EF values of two enantiomers were slightly observed to deviate from 0.5 in T. molitor larvae, it had not been attributed to enantioselective degradation due to faster degradation and enantiomerization (Fig. S1). That is, rac-furalaxyl might not enantioselective degrade in T. molitor larvae also.

\section{Conclusion}

In our experiment, the enantiomerization and enantioselective bioaccumulation of furalaxyl enantiomers in T. molitor larvae from wheat bran were investigated by HPLC-MS/MS based on a ChiralPAK IC. The results indicated that exposure of enantiomers R-furalaxyl and S-furalaxyl in T. molitor larvae revealed significant enantiomerization with formation of the $\mathrm{R}$ enantiomer from the $\mathrm{S}$ enantiomer, and viceversa. Enantiomerization was not observed in wheat bran during the period of 21 days. In addition, there was an obvious enantioselective bioaccumulation in the T. molitor larvae with a preferential accumulation of S-furalaxyl. This suggests that enantiomerization could make the biological effect of racemate mixture complicated with effective enantiomer transformed to the inactive enantiomer. Enantiomerization should be considered to be an important factor influencing the enantioselective behaviors of chiral pesticides in organisms in addition to 
actual degradation and metabolism.

\section{Acknowledgments}

This work has been funded by the National Natural Science Foundation of China (No. 21477152).

\section{Appendix A. Supplementary material}

Supplementary data associated with this article can be found in the online version at http://dx.doi.org/10.1016/j.ecoenv.2017.07.041.

\section{References}

Cabras, P., Meloni, M., Pirisi, F.M., Cabitza, F., 1985. Behavior of acylanilide and dicarboximidic fungicide residues on greenhouse tomatoes. J. Agr. Food Chem. 33 86-89.

Diao, J., Lv, C., Wang, X., Dang, Z., Zhu, W., Zhou, Z., 2009. Influence of soil properties on the enantioselective dissipation of the herbicide lactofen in soils. J. Agr. Food Chem. 57, 5865-5871.

Effenberger, F., Burkard, U., Willfahrt, J., 1986. Aminosäuren, 4. Enantioselektive Synthese N-substituierter $\alpha$-Aminocarbonsäuren aus $\alpha$-Hydroxycarbonsäuren. Liebigs Ann. Chem. 1986, 314-333.

Friedman, M., 1999. Chemistry, nutrition, and microbiology of D-amino acids. J. Agr. Food Chem. 47, 3457-3479.

Gao, Y., Chen, J., Wang, H., Liu, C., Lv, X., Li, J., Guo, B., 2013. Enantiomerization and enantioselective bioaccumulation of benalaxyl in Tenebrio molitor larvae from wheat bran. J. Agr. Food Chem. 61 (38), 9045-9051.

Gao, Y., Wang, H., Qin, F., Xu, P., Lv, X., Li, J., Guo, B., 2014. . Enantiomerization and enantioselective bioaccumulation of metalaxyl. Chirality 26, 88-94.

Garrison, A.W., 2006. Probing the enantioselectivity of chiral pesticides. Environ. Sci. Technol. 40, 16-23.

Genualdi, S.A., Simonich, S.L.M., Primbs, T.K., Bidleman, T.F., Jantunen, L.M., Ryoo, K.S., Zhu, T., 2009. Enantiomeric signatures of organochlorine pesticides in Asian, Trans-Pacific, and Western US air masses. Environ. Sci. Technol. 43, 2806-2811.

De Geus, H.J., Wester, P.G., De, B.J., Brinkman, U.A., 2000. Enantiomer fractions instead of enantiomer ratios. Chemosphere 41 (5), 725-727.

Hutt, A.J., Caldwell, J., 1983. The metabolic chiral inversion of 2-arylpropionic acids-a novel route with pharmacological consequences. J. Pharm. Pharmacol. 35, 693-704.

Kostaropoulos, I., Papadopoulos, A.I., Metaxakis, A., Boukouvala, E., Papadopoulou-Mourkidou, E., 2001. The role of glutathione S-transferases in the detoxification of some organophosphorus insecticides in larvae and pupae of the yellow mealworm, Tenebrio molitor (Coleoptera: tenebrionidae). Pest Manag. Sci. 57, 501-508.

Lewis, D.L., Garrison, A.W., Wommack, K.E., Whittemore, A., Steudler, P., Melillo, J., 1999. Influence of environmental changes on degradation of chiral pollutants in soils.
Nature 401, 898-901.

Li, Z., Zhang, Y., Li, Q., Wang, W., Li, J., 2011. Enantioselective degradation, abiotic racemization, and chiral transformation of triadimefon in soils. Environ. Sci. Technol. 45, 2797-2803.

Liu, W., Qin, S., Gan, J., 2005. Chiral stability of synthetic pyrethroid insecticides. J. Agr. Food Chem. 53, 3814-3820.

Müller, T., Kohler, H.-P., 2004. Chirality of pollutants-effects on metabolism and fate. Appl. Microbiol. Biot. 64, 300-316.

Maier, N.M., Franco, P., Lindner, W., 2001. Separation of enantiomers: needs, challenges, perspectives. J. Chromatogr. A 906, 3-33.

Nillos, M.G., Qin, S., Larive, C., Schlenk, D., Gan, J., 2009. Epimerization of cypermethrin stereoisomers in alcohols. J. Agr. Food Chem. 57, 6938-6943.

Palla, O., Mirenna, L., Colombo, L., Zini, G., Filippini, L., Zanardi, G., 2001. Fungicidal compositions based on (N-phenylacetyl-N-2, 6-XYLYL) methyl alaninate. Google Patents.

Prabhakar, S., Chen, M.S., Elpidina, E., Vinokurov, K., Smith, C., Marshall, J., Oppert, B., 2007. Sequence analysis and molecular characterization of larval midgut cDNA transcripts encoding peptidases from the yellow mealworm, Tenebrio molitor L. Insect Mol. Biol. 16, 455-468.

Price, T., Fox, P., 1986. Studies on the behaviour of furalaxyl on pythiaceous fungi and cucumbers in recirculating hydroponic systems. Crop. Pasture Sci. 37, 65-77.

Qin, S., Gan, J., 2007. Abiotic enantiomerization of permethrin and cypermethrin: effects of organic solvents. J. Agr. Food Chem. 55, 5734-5739.

Rouchaud, J., Metsue, M., Benoit, F., Ceustermans, N., Vanachter, A., 1989. Fate of the fungicide furalaxyl in the nutrient solution of tomato crops by the nutrient film technique. J. Agr. Food Chem. 37, 492-495.

Sun, D., Pang, J., Qiu, J., Li, L., Liu, C., Jiao, B., 2013. Enantioselective degradation and enantiomerization of indoxacarb in soil. J. Agr. Food Chem. 61 (47), 11273-11277.

Tarrier, N., Pilgrim, H., Sommerfield, C., Faragher, B., Reynolds, M., Graham, E., Barrowclough, C., 1999. A randomized trial of cognitive therapy and imaginal exposure in the treatment of chronic posttraumatic stress disorder. J. Consult. Clin. Psychol. 67, 13.

Testa, B., Carrupt, P.A., Gal, J., 1993. The so-called "interconversion" of stereoisomeric drugs: an attempt at clarification. Chirality 5, 105-111.

Wang, X., Zhu, W., Qiu, J., Wang, D., Zhou, Z., 2017. Enantioselective metabolism and enantiomerization of benalaxyl in mice. Chemosphere 169, 308-315.

Wang, Y., Guo, B., Gao, Y., Xu, P., Zhang, Y., Li, J., et al., 2014. Stereoselective degradation and toxic effects of benalaxyl on blood and liver of the chinese lizard eremias argus. Pestic. Biochem. Phys. 108 (1), 34.

Wiegert, R.G., Evans, F.C., 1967. Investigations of secondary productivity in grasslands.

Xu, P., Liu, D., Diao, J., Lu, D., Zhou, Z., 2009. Enantioselective acute toxicity and bioaccumulation of benalaxyl in earthworm (Eisenia fedtia). J. Agr. Food Chem. 57, 8545-8549.

Ye, J., Zhao, M., Liu, J., Liu, W., 2010. Enantioselectivity in environmental risk assessment of modern chiral pesticides. Environ. Pollut. 158, 2371-2383.

Zhang, H., Wang, X., Jin, L., Qian, M., Wang, X., Xu, H., Qi, P., Wang, Q., Wang, M., 2012. Enantioselective determination of acylamino acid fungicides in vegetables and fruits by chiral liquid chromatography coupled with tandem mass spectrometry. J. Sep. Sci. 35, 1869-1876. 